UNPLUGGED

\title{
We All Became Wombats! From Pillar to Post with the Analogy between Publishing Scientific Prose and Producing Cubic-Shaped Poop'
}

\author{
Sébastien Liarte $1,2,3,4$

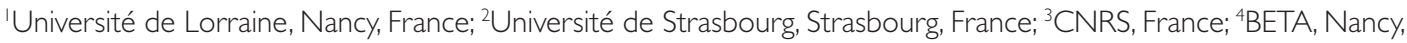 \\ France
}

$R$ esearchers are well aware that university breaks are often the most inspiring periods for writing, in particular academic articles. Still, one cannot prevent our relatives from questioning why we are not more available for them. This is what happened when my daughter came to me with her bag full of tricky questions.

- Daddy, come play with me!

- (grumbling as I come out of my mental focus). Not right now, honey, I'm working.

- (the little angel was getting slightly pissy) But ... it's Christmas break! You're supposed to be on holidays! Just like your students! Just like us!

- (feeling like I had to justify myself) Yes ... alright ... I know sweetheart ... but I have to finish this paper.

- But you always have a paper to finish ... or to start... I can't believe it! Why do you always keep working on your articles ... Are you less gifted than the others? Do you have to work harder than the others?

- (damnit, sneaky little girl! This was not even a silly question) Mhmmm ... You're probably right ... But you know, publishing in an academy journal is not that easy. It is really hard work!

- But why? What is an article actually made of?

- (alright, let's try to keep her mind off of trickier questions by talking about my job) Well ... an article, you know, is quite a simple thing: you report your research to a broader audience. Just picture your presentations during your science classes, you see?

- (obviously rejoiced, as she seemed to have understood it all in a flash) Alright, so it's very easy, you just write down your thoughts, describe the experience, share the results and ... tadam ! -
- (getting into details) Yes, you're spot on ... well, not fully but that is how it roughly goes. And there are a few implied rules to follow on top of that.

- Implied ... rules? What are you talking about?

- (Alright, calm down Professor Snape, you are not talking to your students. Well, anyway even they are usually clueless about what I mean.) There are rules that have to be followed but are not written anywhere.

- (Clearly not happy with my answer) How do we get to know them then?

- You learn them from experience, or from being taught by someone who knows them.

- Oh, that's right! Just the way the teacher does with us.

- Yes, you are lucky to have a teacher who shows you the way things work. And just like your teacher, there are people over here, who assess our work, give us a grade, and tell us how we can improve it. Even though most of the time, they just tell us that our subject is not that interesting and that we should not waste our breadth over it.

- (she is not one to give up that easily) Most of the time? Everyone says that? So everyone sucks?

- Some people more than others ... well, some have to spend more energy than others at work ... and it depends on the journal you are targeting ... But yes, that is how it goes.

- (Now she seemed really surprised) Alright, so publishing is somehow exceptional, like an accomplishment ... Shouldn't it be the other way around, if publishing is the purpose of your job?

- You are right ... But there are several reasons why it is not that straightforward.

*Corresponding author: Sébastien Liarte, Email: sebastien.liarte@univ-lorraine.fr

1. My acknowledgement goes to Maxime Duda for his conversational English language skills. 
- Ah ... I see. In fact, you guys, the researchers in management... you are wombats!

- (first time I hear that word) Pardon me young lady?

- Wombats! Dad, do you even know about wombats? The wombat is such a great animal! It is the only living creature who produces cubic shaped doo-doos.

- Great... I'm trying to tell you things about my daily work in an adult way and you bring it down to bathroom jokes.

- No way, Dad, it's exactly the same thing! Making a cubic poop is just like publishing an article: it is really, really difficult. No colon is ever naturally made for that, no one shows you how to do it and that is what makes wombats so unique. They pile up their most beautiful cubic shaped dumps, and at the end, the one with the highest pile of cubic dejections becomes the leader!

- Your comparison is funny ... because in our work community, the one who manages to release the most impressive articles in the best journals, the one who stacks the most written production, turns out to become the boss! Our top researcher!

- That is exactly what I'm telling you, you guys are wombats! And of course, these animals get stronger over and over because those who manage to make the most cubic-shaped poops are those who survive the longest ... And as a result, they mate among themselves!

- That's right! This is how Evolutionary mechanisms go: some of us adapt to our environment and get stronger, we become experts in cubic poops. . .gahhh. . . I mean experts in writing more accurate articles. We emulate each other as we are living among our wombat counterparts.

- Alrighty, I think I have seen that on YouTube ... First of all, their diet is important. Apparently, they eat very dry things to produce the perfectly shaped dejection. On top of that, it seems like some parts of their colon have a different springiness. That is how you get the best cubic-shaped poop.

- Same goes for our shi ... sorry, I mean our sheets ... of paper, the best newspapers and journals: an environment that offers the best resources (dry food for wombats, advice from close colleagues for researchers), a 'special personal talent' (a more flexible intestine or writing skills) and a lot of work to achieve greatness.

- See, I was right, Daddy, you're all wombats!

- You could see it this way ...

- But... why are you doing this? The wombat has its own reasons ... For example, it is an animal with poor eyesight. And everyone knows that a stack of poop is more visible from afar and smells stronger.
- Well, you could say the same about us! Sometimes finding out who works harder, or better, is useful. It is not an easy thing to sort out as our works are difficult to evaluate and compare. In a perfect world, you would have to read them all, this is a hell of a hard work ... So, stacks of pretty cubes are handy! Evaluation boards are sometimes just a group of shortsighted wombats who feel lost in the middle of stacks of cubic-shaped poop.

- (Stubborn little thing, she would not give up) But who decides if your poop is truly cubic? How do they assess it?

- Well, there's a whole system of evaluation behind it. There are heads of academic journals and chief editors, who ultimately decide whether the poop is cubic enough to be part of the stack. Specialists and evaluators assess the cubic-ness, and even sometimes advise us on shaping them best. Then, on a collective level, there are filters that grade the quality of the poop, those are the academic journal's rankings.

- $\quad$ But everyone plays that game? Isn't there anyone who is trying to do something else? Like a triangular poop?

- Well, some people do not get in line, indeed! If for some reason, we don't want to make cubic-shaped poop, we can try triangles, balls, etc., like books, press articles, videos. But the problem remains: it is like squaring the circle ... and even worse, the stacks might smell less. Other people try to change the filter, the evaluation rules to determine the very definition of what is cubic or not. Tools can be changed to prove that triangles are in fact cubes. But at the end of the day, stacking remains difficult ...

- $\quad$ (with a little bit of mischief) Oh yes, your rankings are like thermometers. If you want to live in a country with $20^{\circ}$ all year round, you can move to Marrakech, or you can build a thermometer that always points to $20^{\circ} \mathrm{C}$... But if you go for the second option, it will not prevent you from feeling cold anyway.

She eventually stared at me with a stern look, and raised one last meaningful question.

- But don't you feel sad sometimes? A wombat is a cute animal, but... you, you keep striving to get better results, better-shaped poop, working always harder ... doesn't it ever feel absurd and sad?

- Ah well ... my sweet darling ... I leave that opinion to you. On my end, I have to go back to my shapeless piece of poop ... and stack my pile until it is high and smelly enough. 